LBL-29971

SC-MAG-320

\title{
QUADRUPOLE MAGNETS FOR THE SSC COLLIDER*
}

C.E. Taylor, P. Barale, R. Benjegerdes, S.Caspi, D. Dell'Orco, D. Fritz, W. Gilbert, A. Lietzke,

K. Mirk, C. Peters, R. Scanlan, and

A. Wandesforde

\section{Lawrence Berkeley Laboratory \\ University of California \\ Berkeley, California 94720}

\author{
12th International Conference on \\ Magnet Technology \\ June 23-28, 1991 \\ Leningrad, USSR
}

*This work was supported by the Director, Office of Energy Research, Office of High Energy and Nuclear Physics, Division of High Energy Physics, of the U.S. Department of Energy under Contract No. DE-AC03-76SF00098 
LBL-29971

Presented at the 12th International Conference on Magnet Technology, Leningrad, USSR, June 23-28, 1991, and to be published in the Proceedings

\section{Quadrupole Magnets for the SSC Collider}

P. Barale, R. Benjegerdes, S. Caspi, D. Dell'Orco, D. Fritz, W.Gilbert, A. Lietzke, K. Mirk, C. Peters, R. Scanlan, C.E. Taylor, A. Wandesforde 


\section{Quadrupole Magnets for the SSC Collider*}

C. E. Taylor, P. Barale, R. Benjegerdes, S. Caspi, D. Dell'Orco, D. Fritz, W. Gilbert, A. Lietzke, K. Mirk, C. Peters, R. Scanlan, and A. Wandesforde

Lawrence Berkeley Laboratory

University of California

Berkeley, CA 94720 in the coil ends; end turns must be appropriately spaced to give uniform gradient in an integral sense [3], and to limit the maximum field at the windings; in addition, the spacers must be accurately shaped to give good mechanical support to the cable. All of the models tested to date have the same basic end design in which the inner coil lead has severe bends in the high-field region as it exits from the coil; in addition, in this region, the lead support structure was shaped by hand. In later models, built but not yet tested, the ends have been redesigned to eliminate sharp bends, and the need for "hand shaping," thus achieving better cable support. Figure 2 shows a new set of coil end parts for the two layers. Note the slot in the split pole piece for the lead. The design of each end turn follows an approximate "constant perimeter" shape for ease of fabrication; final adjustment of the shape is determined empirically from model coils.

\section{INTRODUCTION}

Each ring of the SSC Collider has 832 5-m long quadrupole magnets. Magnet parameters and cable specifications are described in Ref. 1. Operating gradient is $211 \mathrm{~T} / \mathrm{m}$ at $6500 \mathrm{~A}$ in a $40 \mathrm{~mm}$ coil bore. We have designed, constructed, and tested $1 \mathrm{~m}$ and $5 \mathrm{~m}$ models of the quadrupoles.

\section{COILS}

The windings are arranged in a two-layer " $\cos 2 \theta$ " pattern around a circular bore as shown in Fig. 1 with 8 inner turns and 13 outer turns. The cable has a 1.2 degree "keystone;" wedge-shaped copper spacers are inserted at the locations shown for two reasons: to provide a "Roman arch" structure without internal support, as well as a uniform quadrupole field. Details of the coil crosssection are given by Caspi [2].

Coils are wound with $135 \mathrm{~N}$ conductor tension. At each end turn, $0.1 \mathrm{~mm}$ of additional Kapton insulation is added by hand-wrapping and about $0.1 \mathrm{~mm}$ of fiberglass cloth, partially impregnated with B-stage epoxy, is added to the inside and outside of a small region of the ends for mechanical reinforcement. The coils are then placed in a fixture and compressed to about $70 \mathrm{MPa}$ azimuthally and $9 \mathrm{kN}$ force axially, while being heated to $130 \mathrm{C}$ in a mold. During heating, the coil is compressed to its final size and the epoxy is polymerized which makes the coil sufficiently self supporting to be removed from the winding fixture and assembled.

Much of the complexity and difficulty in design and construction of 40-mm bore quadrupoles with "wide" cable is

\footnotetext{
*Work supported by the Director, Office of Energy Research, Office of High Energy and Nuclear Physics, High Energy Physics Division, U.S. Department of Energy, under Contract No.DE-AC03-76SF00098.
}

Fig. 1 Crosssection cut from $1 \mathrm{~m}$ model QC1.

CBB 916-4509

Voltage taps are installed at the ends of each pole turn of each coil so that the precise origin of quenches can be determined.

The eight coils are assembled on a temporary horizontal mandrel and preshaped Kapton sheets are installed between layers and on the outer coil surfaces for electrical insulation. 


\section{COLLARS}

Structural support is provided by interlocking collars, preassembled for ease of assembly, into $146 \mathrm{~mm}$ long collar "packs," fastened with pins, and glued with epoxy to keep them straight. There are two symmetrical collar lamination shapes; the larger lamination has keyways and is stacked alternately with the small lamination which provides uniform continuous support of the windings at the pole turns. The small lamination is $0.1 \mathrm{~mm}$ thicker to provide a small clearance between the large, interleaved laminations for ease of assembly. Structural analysis of this collar is given by D. Dell'Orco [4].

Fig. 2 Set of inner and outer lead end spacers.

Fig. 3 End view of the quadrupole collaring press showing 4 main collaring platens (each driven by 3 cylinders) and 4 keyinsertion platens (each driven by 7 cylinders).

Figure 3 shows a crosssection of the collaring press. The coil is first collared to half of final prestress by inserting the keys halfway; the end structure is then added; finally in a second operation the keys are fully inserted and prestress increased to about $40 \mathrm{MPa}$. This two-step procedure limits the maximum stress concentration that would result if each collar pack reached full prestress in a single step while the coils immediately adjacent to the collar pack remained unloaded.
Fig. 4 Longitudinal cross-section of the magnet end showing the coil end support structure and splice plates.

Figure 4 shows a crosssection of the magnet end. An aluminum ring (Tapered End Clamp) applies preload to the coils through a tapered fiberglass-epoxy End Insulator. The taper of the End Insulator (collet) is matched to the taper of the Tapered End Clamp in an effort to keep the radial preload uniform. The radial preload is applied by axially squeezing the Tapered End Clamp onto this tapered End Insulator. The End Insulator has 4 identical azimuthal sections in order to provide easy access and support for the cables leading out to splice plates (where all layer-to-layer and quadrant-to-quadrant splicing is accomplished). Channels are provided in the End Insulator for the safe egress of strain gage and voltage tap leads (not required in production models). Upcoming models will have the Tapered End Clamp secured to the Yoke End Plate (via the Retaining Ring shown).

\section{YOKE}

The $267 \mathrm{~mm}$ diameter iron yoke laminations are assembled into $146 \mathrm{~mm}$ long sections or blocks (later models have $460 \mathrm{~mm}$ blocks); a thin layer of epoxy adhesive between laminations provides rigidity. At each end of the magnet, a 5 $\mathrm{cm}$ long solid yoke block is used (Fig. 4). To assemble the cold mass, the lower half of the yoke is placed in the lower half of the $4.7 \mathrm{~mm}$ thick stainless steel "skin;" the collared coil is set into place followed by the upper yoke and skin. The collars are centered in the yoke by tabs, which fit keyways in the yoke, contacting the yoke only on the two sides of the keyway; thus the collar is accurately centered while remaining free to deform with magnet loading or thermal contraction. Figure 5 shows the cold mass crosssection. At $46 \mathrm{~cm}$ intervals along the magnet, there is an opening in the shell to allow an alignment key (attached to 
the tooling - not shown) to engage a keyway in the yoke blocks shown in Figures 5 and 6 . These keys ensure that the yoke blocks have accurate azimuthal alignment along the entire length. The azimuthal twist variations of QCC-401 (first $5 \mathrm{~m}$ model) was less than $0.22 \mathrm{mrad}$ after release from the welding press.

After welding, a key (shown in Fig. 6) is engaged with the keyway and welded in place, sealing the shell opening; a permanent fiducial feature is attached to the key for surveying.

Fig. 5 Crosssection of the cold mass.

Fig. 6 Cutaway section of the cold mass showing the yoke alignment key.

After the skin is welded, an axial load of about $22 \mathrm{kN}$ is applied directly to the coil end by jack screws, compressing the magnet end axially between the End Plate and the Yoke End Plate (which is solidly gripped by the shell). Electrical connections are then made between the eight coils by soldering lead pairs. Each cable pair is tightly supported by channels machined into an insulating (epoxy glass) splice plate.

\section{TESTING}

The cold mass is tested in a horizontal test cryostat in static liquid helium at $1 \mathrm{~atm}$ pressure.

Training histories for the first three $1 \mathrm{~m}$ models are shown in Figure 7. Only $4.3 \mathrm{~K}, 16 \mathrm{~A} / \mathrm{s}$ ramp rate data is shown unless otherwise noted.

All quenches originated in the pole turn. Training quenches start predominantly in the inner coil; plateau quenches start predominantly in the outer coil (as expected [1]).

The first $1 \mathrm{~m}$ model, QC1 (Fig. 7a) started training at $6809 \mathrm{~A}$, well above the maximum expected operating current $(6500 \mathrm{~A})$; it reached a plateau at $7988 \mathrm{~A}$ at $4.3 \mathrm{~K}$ and $9908 \mathrm{~A}$ at $1.8 \mathrm{~K}$; after the first thermal cycle, there were three retraining quenches starting at $7367 \mathrm{~A}$, and no retraining after a second thermal cycle. The quenches started predominantly on the lead side of the inner pole turn near the lead end.

QC2 (Fig. 7b) trained slowly, although the second quench was at design current, and had to be retrained after each of two thermal cycles; one is shown in Figure 7b. These quenches were predominantly located in the coil end where the lead makes a sharp bend as it exits the inner turn. It was subsequently determined that this region was inadequately supported. The maximum current reached at $4.3 \mathrm{~K}$ was 8046 A; $1.8 \mathrm{~K}$ testing was stopped at $8967 \mathrm{~A}$, well below the short-sample limit.

Fig. 7a,b,c Training history for the first three $1 \mathrm{~m}$ model models $\mathrm{QC1}$, $\mathrm{QC} 2$, and QSC-403. 
QSC-403 (Fig. 7c) incorporated the above-mentioned Tapered End Clamp replacing a bolted stainless steel clamp used in QC 1 and QC 2. Voids (as discovered in an autopsy of QC 2) were filled with low-shrink epoxy. Pole-turn winding tension was maintained until coil curing was finished. There was very little training. The lower plateau current resulted from a change in cable specification.

The first $5 \mathrm{~m}$ magnet, QCC-401, has coil design and assembly features similar to QC 1 , and an end clamping structure similar to QSC-403. It reached design current on the second quench, and had moderate training (Fig. 8) reaching $7389 \mathrm{~A}$, its short-sample limit, at $4.3 \mathrm{~K}$. Two quenches started in the coil ends and all but one started within $1 \mathrm{~m}$ of either end.

Fig. 8 Training history for $5 \mathrm{~m}$ model QCC-401.

This quench location pattern leads us to conjecture that it might be related to details of the coil end restraint. In the second $5 \mathrm{~m}$ model, we added the Retaining Ring shown in Fig.ure 4 (not present in the models tested to date) which secures the Tapered End Clamp ring to the Yoke End Plate, so that there cannot be axial motion between the collared coil and yoke/skin; without this, as the pressure is removed from the skinning press after welding, the magnet shortens by about $1.6 \mathrm{~mm}$ because of tensile hoop stress developed in the shell by the welding, thus causing a gap to open between the Tapered End Clamp and the Yoke End Plate.

Magnetic field measurements were made in the $1 \mathrm{~m}$ magnets using a rotating probe with radial coils [5] operating at the magnet temperature; magnet current is limited to \pm 20 A when warm. The $5 \mathrm{~m}$ magnets were measured with a new $42 \mathrm{~cm}$ long measurement coil, designed and built by Brookhaven National Laboratory (BNL), using tangential coils. The probe operates in a vacuum-insulated "warm finger" in which the measuring coil is maintained at room temperature. This new tangential system was used to remeasure one of our $1 \mathrm{~m}$ quadrupoles which had previously been measured with the radial coil system. The measurements, at room temperature, were in excellent agreement. The first cryogenic test of the new system was in QCC-401 and the results appears in Table 6 along with the 1 $\mathrm{m}$ model results.

Known variations in coil size are present in these first models resulting in part for the observed variations in $b_{5}(12$ pole).
TABLE 6

HARMONIC COEFFICIENTS IN UNITS OF $10^{-4}$

\begin{tabular}{|c|c|c|c|c|c|c|c|c|}
\hline & \multicolumn{2}{|c|}{$\begin{array}{c}\mathrm{I}=3045 \mathrm{~A} \\
\mathrm{QC}-1\end{array}$} & \multicolumn{2}{|c|}{$\begin{array}{c}\mathrm{I}=3045 \mathrm{~A} \\
\mathrm{QC}-2\end{array}$} & \multicolumn{2}{|c|}{$\begin{array}{l}\mathrm{I}=3055 \mathrm{~A} \\
\mathrm{QSC}-403 \\
\end{array}$} & \multicolumn{2}{|c|}{$\begin{array}{l}\mathrm{I}=1013 \mathrm{~A} \\
\mathrm{QCC}-401\end{array}$} \\
\hline $\begin{array}{l}\mathbf{n} \\
2\end{array}$ & $\begin{array}{l}a_{n} \\
0.4\end{array}$ & $\begin{array}{l}\mathrm{b}_{\mathrm{n}} \\
1.6\end{array}$ & $\begin{array}{l}a_{n} \\
-0.3\end{array}$ & $\begin{array}{l}b_{\mathrm{n}} \\
-1.2\end{array}$ & $\begin{array}{l}a_{n} \\
0.41\end{array}$ & $\begin{array}{l}b_{n} \\
2.18\end{array}$ & $\begin{array}{l}a_{n} \\
-0.34\end{array}$ & $\begin{array}{l}b_{n} \\
-2.1\end{array}$ \\
\hline 3 & -1.52 & 0.20 & -1.9 & -0.55 & 0.34 & -0.35 & 0.0 & -0.38 \\
\hline 4 & 0.06 & -0.33 & 0.74 & 0.37 & 1.55 & -0.63 & 1.69 & -1.66 \\
\hline 5 & -0.16 & -0.42 & -0.22 & -0.66 & 0.06 & -2.29 & -0.654 & -4.41 \\
\hline 6 & 0.08 & -0.12 & -0.12 & -0.08 & 0.02 & -0.01 & -0.07 & -0.01 \\
\hline 9 & 0.00 & 0.11 & 0.02 & 0.06 & -0.02 & 0.16 & 0 & 0.22 \\
\hline
\end{tabular}

The effect of magnetization induced by persistent currents agrees well with predictions as described in Ref. [6].

\section{FUTURE PLANS}

We plan to test three additional $1 \mathrm{~m}$ models (two with stainless steel collars) and five additional $5 \mathrm{~m}$ models (three with stainless steel collars) during the next 9 months; these models will incorporate a number of design improvements in the coil end region

After testing at LBL, the $5 \mathrm{~m}$ models will be shipped to the SSC Laboratory, installed in cyrostats similar to the SSC CDM dipole cryostats, and retested.

A contract will be placed by the SSC Laboratory to design a production version of the quadrupoles (with cryostat), and to construct and test a series of production prototypes.

\section{REFERENCES}

[1] C. E. Taylor, et al; IEEE Trans. on Mag., vol 27, No. 2, March 1991.

[2] S. Caspi, "The 40mm SSC Arc Quadrupole - Magnetic Design," SC-MAG-314, LBID-1677, November 1990.

[3] S. Caspi, M. Helm, and L. J. Laslett, "Magnetic Field in the End Regions of the SSC Quadrupole Magnets," MT-12 Conference, Leningrad, USSR, June 23-28, 1991.

[4] D. Dell'Orco, "Finite Element Analysis of the QC Quadrupole Magnet for the Superconducting Supercollider," LBL-29600, October 1989.

[5] M. I. Green, et al; IEEE Trans. on Mag., vol. 24, No. 2, March 1988.

[6] M. A. Green, P. J. Barale, R. W. Benjegerdes, W. S. Gilbert, M. I. Green, R. M. Scanlan, J. Sopher, and C. E. Taylor, "Measurements of Magnetization Multipoles in Four Centimeter Quadrupoles for the SSC," Cryogenic Engr. Conf., Huntsville, AL, June 11-14, 1991. 